\title{
Design of Multi-dimensional Contents Retrieval UI for Mobile IPTV
}

\author{
Jaehee Byeon*, Ju-Hong Song* and Nammee Moon*
}

\begin{abstract}
Since two-way interactive broadcasting service began, remote controls have been fitted with 4 color buttons, which enables interaction and convenience to increase between users and content. Currently, diverse studies on IPTV are in progress. Particularly, as the mobile market rapidly grows, studies on mobile IPTV and on linkage with other media are constantly increasing. However, mobile IPTV has never been studied until now. In that sense, this present study attempted to design a mobile-based IPTV UI that could use a multi-dimensional search method based on consistent criteria for content search. As a result, the proposed IPTV UI is fitted with more usability and functionality for 4 color buttons. The UI designed in this study was compared to the IMDb Android Application, which uses GOMS-KLM. The results showed that the performance process was reduced by three stages, and that the performance time was reduced by more than $17.9 \%$. Therefore, the conclusion can be reached that the proposed $\mathrm{UI}$ is effective for a fast search of contents.
\end{abstract}

Keywords-Mobile IPTV, UI(User Interface), Contents Browser, EPG, Personalized Content, Interactive Service

\section{INTRODUCTION}

Since the emergence of black-and-white TV, TV has been through a series of advancement, which has led to its evolution into IPTV. Particularly, IPTV combined with the two-way interaction of TV and communication extends the roles of TV as a unilateral content receiver for each broadcasting company including terrestrial, cable, and satellite ones, providing a wide range of services for TV users [1,2]. With the dramatic development of broadband communication networks over the past decade, IPTV has been commercialized, and its scope has been extended to personalized terminals such as web-based or mobile-based IPTV functioning as a TV platform using TV applications on TV-based IPTV. Furthermore, various studies on two-way interaction, personalization, and the extended bundle service of IPTV are in progress $[1,3,4]$. Existing TVbased IPTV service is largely divided into real-time channel service, VOD service, and two-way service. Above all, content for VOD service preferred among users is expected to grow and that it will then be followed by an increase in demand for such content. Moreover, thanks to the twoway of IPTV, the push-oriented communication between service providers and users has evolved into interactive push-and-pull communication, calling for significant interaction between the two parties.

※ This research was supported by Hoseo University's Academic Research Fund in 2010 (No. 2009-0545)

Manuscript received August 20, 2010; accepted January 4, 2011.

Corresponding Author: Nammee Moon

* Dept. of IT Application Tech, Hoseo Graduate School of Venture, Seoul, Korea (bjaeh9188@gmail.com, juhongeda@naver.com,mnm@hoseo.edu) 
In addition, with the growth spurt of the technology associated with mobiles and terminals, studies on mobile-based IPTV have been performed more actively including solving the disadvantageous low-speed processing of mobile terminals and the common characteristics of IPTV and mobile technology in terms of two-way interaction, personalization, and bundle-based diverse and extensive services[3,5,6]. However, studies performed so far have mostly focused on technically applying TV-based IPTV to mobile terminals, so there has been no UI adapted to mobile terminals[1,4,5,6]. Also, the content browsing criteria suggested by the study on TVbased IPTV content recommendation search system, which uses associated search techniques, are not generally applicable, so mobile IPTV is likely to fail to browse a single content that a user might demand until now[7].

A mobile-based IPTV UI with improved usability based on a contents search standard consistent with 4 color buttons was designed in this study.

\section{RELATED WORK}

In this section, we examined a mobile device UI, remote controller with 4 color buttons, preferences for multimedia contents browsing criteria, and the GOMS-KLM as follows.

\subsection{Mobile Device UI}

Technically, mobile terminals have developed a lot on account of increasing demands for such terminals and the emergence of diverse content. Most of all, the recent boom in the smartphone market has driven the evolution of various mobile devices including mobile phones, PMPs, and MP3Ps. In the meantime, the problematic and controversial processing speed of mobile terminals has improved to a great extent $[8,9,10]$. Subsequently, a plethora of applications have been launched. These applications are fit for the characteristics of mobile terminals including two-way interaction, personalization, and the extensibility of bundle service.

The comparative analysis of UIs on mobile terminals currently in the market found that every mobile terminal basically provides 4 direction keys or 4 quick-views, although screen splits are different depending on the characteristics of content adopted for each mobile terminal by manu-
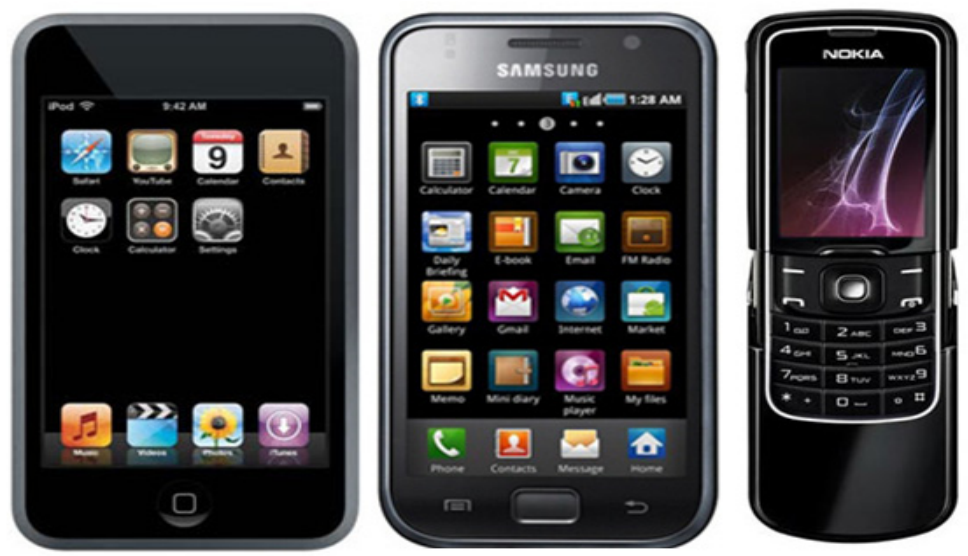

Fig. 1. Mobile Device UI (Left : Apple iPod, Center : Samsung Galaxy S, Right : Nokia) 
facturers. The reason why is because mobile terminals are limited in size changes, and also users are accustomed to using 4 buttons. This finding from the analysis suggests that 4 button layouts are the most usable and effective for portable mobile terminals.

The figure below shows the UIs of mobile devices like Apple, Samsung and Nokia.

\subsection{Remote Controller}

Here, the remote controller model fitted with 4 color buttons is discussed.

As seen in the design schematic, color buttons are designed to work separately from those for volume control, surfing, and other basic functions. Consequently, the 4 color buttons could be diversified and extended to support content browsing and have new featured added to them [11]. UI design using color is a frequently used method. It emphasizes certain contents or divides contents with the same characteristics. Color is especially used in mobile UIs to emphasize information or to create unity, and is used for text or icons [12].

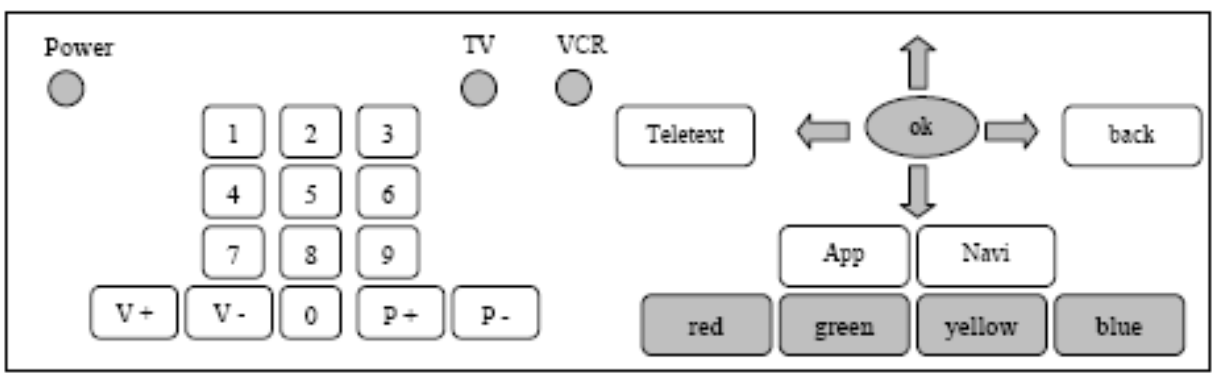

Fig. 2. A conceptual model of a remote control

\subsection{Preferences for multimedia content browsing criteria}

The appearance of IPTV has made viewing many different contents at the time desired, possible for users. Accordingly, the fast and convenient search of contents within IPTV has become an important issue.

The following table shows the results of examining top search standard preferences according to IPTV contents.

As shown in the table, the search standards were found to be similar regardless of the type of contents. This indicates that the user has similar search standards when searching for any type of

Table 1. Content-specific top preferences for browsing criteria

\begin{tabular}{c|c|c|c|c}
\hline RANK & Drama & Films & Entertainment & Current Affairs \\
\hline 1 & Title & Title & Title & Title \\
\hline 2 & Genre & Genre & Performer & Genre \\
\hline 3 & Hero & Hero & Rating & Rating \\
\hline 4 & Rating & $\begin{array}{c}\text { Recommendation } \\
\text { Level }\end{array}$ & Genre & $\begin{array}{c}\text { Recommendation } \\
\text { Level }\end{array}$ \\
\hline 5 & & Director & $\begin{array}{c}\text { Recommendation } \\
\text { Level }\end{array}$ & \\
\hline 6 & & $\begin{array}{c}\text { Number of } \\
\text { audience }\end{array}$ & & \\
\hline
\end{tabular}


content. Consequently, for ease of use, rather than content-specific different approaches, consistent browsing should be provided [13].

\subsection{GOMS-KLM}

A UI is a tool of communication between a device and a person, and has an element of interaction. Therefore, visual expression is important when a user gains information through a UI. Thus there is the need for a theory that can predict the efficiency and appropriateness of UIs, for instance, Fitts' law, Hick's law, and the GOMS model.

The GOMS model, in particular, is a method of predicting how long it will take for a skilled user to perform a task. The time that it will take is considered in terms of the following four elements: goals, operators, methods and selection rules.

- Goals: What the user aims to do through the interface.

- Operator: The recognition process and actual actions needed to reach the goal.

- Method: The process to reach the goal.

- Selection rules: Rules that can be selected and used to reach the goal.

The KLM (Keystroke-Level Model) is the most commonly used model of prediction out of the GOMS models. KLM is a method of analyzing user actions that can be observed. The time needed for the user to perform the actions is calculated, and then the total time needed for the user to perform the entire task is predicted based on this time through a formula (1) [14].

$$
\mathrm{T}_{\text {excute }}=\mathrm{T}_{\mathrm{k}}+\mathrm{T}_{\mathrm{p}}+\mathrm{T}_{\mathrm{H}}+\mathrm{T}_{\mathrm{D}}+\mathrm{T}_{\mathrm{M}}+\mathrm{T}_{\mathrm{R}}
$$

The operating elements of formula (1) are as follows:

Table 2. Operator Elements of KLM

\begin{tabular}{|c|c|c|}
\hline Operator & Description and Remarks & Time(s) \\
\hline $\mathrm{K}$ & Keying: The time it takes to type or press a button. & 0.22 \\
\hline $\mathrm{P}$ & Pointing: The time it takes to point to a subject using a mouse or other tool. & 1.10 \\
\hline $\mathrm{P} 1$ & Clicking: The time it takes to click the mouse. & 0.20 \\
\hline $\mathrm{H}$ & $\begin{array}{l}\text { Homing: The time it takes for the user to place his or her hand on the key- } \\
\text { board or other device. }\end{array}$ & 0.40 \\
\hline $\mathrm{D}$ & Drawing a line: The time it takes to draw a line using the mouse. & $\begin{array}{l}\text { Differs according to } \\
\text { length of line }\end{array}$ \\
\hline M & Mentally preparing: The time it takes to mentally prepare for the next action. & 1.35 \\
\hline $\mathrm{R}$ & Responding: The time it takes for the system to respond. & $\begin{array}{l}\text { Differs according to the } \\
\text { system response time. }\end{array}$ \\
\hline
\end{tabular}




\section{Multi-dimensional Contents Retrieval UI for Mobile IPTV}

A multi-dimensional mobile IPTV contents search UI that can be used consistently, regardless of the type of multimedia contents, was examined.

The multimedia contents menu proposed uses 4 color buttons to divide the contents into 4 groups and combines the search preference rates for browsing contents. The type proposed is a user-focused multi-dimensional contents search menu. The search menu materialization environment consisted of Design Studio 2.2.2218.322. The method of proposal was to set a color value for each of the different types of contents and to allow the user to create his or her own combination of search standard. The user can consider the characteristics of the contents and the contents can be presented effectively on the small screen of the device.

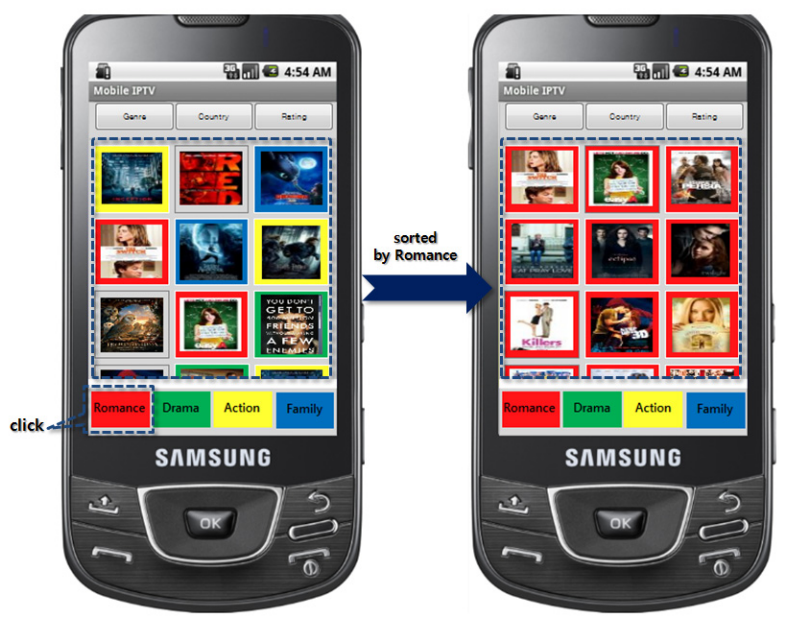

Fig. 3. Multi-dimensional Contents Retrieval UI

\subsection{KLM analysis}

In order to predict the evaluation of the multi-dimensional contents retrieval UI for mobile IPTV, the IMDb Android Application was used as a subject of comparison [15]. IMDb is the largest online data service in the world and it is also a major player in films. It focuses on U.S. dramas, TV and film contents, and is useful for searching related materials and trailer clips. Over 250,000 users around the world have using this application. Therefore, it was selected as the one for comparison. It shares the common point with proposed retrieval UI by providing an android-based UI related to contents search. The task of experiment is the search for the film as the title of "The Switch" in romance genre. The standards of the experiment were as follows:

- The DB is the same.

- The mobile devices used in the experiment are the same.

- Functions not included in each of the UIs are excluded.

- The experiment starts based on the first page shown on the screen of the UI.

- The responding time of each of the UIs is the same. 
Table 3. A comparison of the KLM performance processes of the IMDb and proposed Uls.

\begin{tabular}{|c|c|}
\hline IMDb & Multi-dimensional Contents Retrieval UI \\
\hline $\begin{array}{l}\text { 1. The hand is placed on the screen of the mobile } \\
\text { device }(\mathrm{H}) \\
\text { 2. Mental preparation time (M) }\end{array}$ & \\
\hline $\begin{array}{l}\text { 3. The hand is placed on an appropriate place on the } \\
\text { screen }(\mathrm{P})\end{array}$ & $\begin{array}{l}\text { 1. The hand is placed on the screen of the mobile } \\
\text { device }(\mathrm{H})\end{array}$ \\
\hline $\begin{array}{l}\text { 4. The user moves to the Popular Movies by Genre } \\
\text { menu by dragging (D) }\end{array}$ & $\begin{array}{l}\text { 2. Mental preparation time }(\mathrm{M}) \\
\text { 3. The hand is placed on an appropriate place on the }\end{array}$ \\
\hline $\begin{array}{l}\text { 6. The user clicks on the Popular Movies by Genre } \\
\text { menu }(\mathrm{K})\end{array}$ & $\begin{array}{l}\text { 4. The user clicks on Movies }(\mathrm{K}) \\
\text { 5. Mental preparation time }(\mathrm{M})\end{array}$ \\
\hline $\begin{array}{l}\text { 7. The user moves to the Romance menu by drag- } \\
\text { ging (D) }\end{array}$ & $\begin{array}{l}\text { 6. The user clicks on Genre }(\mathrm{K}) \\
\text { 7. Mental preparation time }(\mathrm{M})\end{array}$ \\
\hline $\begin{array}{l}\text { 8. Mental preparation time }(\mathrm{M}) \\
\text { 9. The user clicks on the Romance menu }(\mathrm{K}) \\
\text { 10. Mental preparation time }(\mathrm{M}) \\
\text { 11. The user clicks on the the Switch movie }(\mathrm{K})\end{array}$ & 8. The user clicks on the "The Switch" movie (K) \\
\hline
\end{tabular}

- The drawing a line time of each of the UIs is the same.

- The drawing a line time of each of the UIs be used on hand instead of using the mouse.

- The film genre classification system and order of each of the UIs are the same.

- The point right up to before search of the film is considered the performance process.

- There is mentally preparing time whenever the user goes down to a sub-menu.

- The user is skilled at using both UIs and the UI settings are set to fit the user.

The results show that the proposed UI has four less performance process stages compared to the IMDb UI. This is because the film search standard was multi-dimensional and the process of moving to the sub-menu was ommitted after the selection of contents. The following is a calculation of the performance time (T) of the IMDb and KLM performance processes.

As a result of calculating the performance times of the IMDb and proposed UIs, the performance time of the IMDb UI was $\left(1.35+2 \mathrm{~T}_{\mathrm{D}}\right)$ seconds longer than that of the proposed UI. Therefore, it could be confirmed that performance time was reduced by around more than $17.9 \%$ with the proposed UI compared to the IMDb UI, and that the application of a multi-dimensional standard provides a more useful contents search function.

Table 4. A comparison of the KLM performance times of the IMDb and proposed Uls.

\begin{tabular}{c|c}
\hline & \multicolumn{1}{c}{ Time } \\
\hline & $\mathrm{T}=\mathrm{T}_{\mathrm{H}}+\mathrm{T}_{\mathrm{M}}+\mathrm{T}_{\mathrm{P}}+\mathrm{T}_{\mathrm{D}}+\mathrm{T}_{\mathrm{M}}+\mathrm{T}_{\mathrm{K}}+\mathrm{T}_{\mathrm{D}}+\mathrm{T}_{\mathrm{M}}+\mathrm{T}_{\mathrm{K}}+\mathrm{T}_{\mathrm{M}}+\mathrm{T}_{\mathrm{K}}$ \\
& $=\mathrm{T}_{\mathrm{H}}+4 \mathrm{~T}_{\mathrm{M}}+\mathrm{T}_{\mathrm{P}}+2 \mathrm{~T}_{\mathrm{D}}+3 \mathrm{~T}_{\mathrm{K}}$ \\
& $=0.40+5.4+1.1+0.66+2 \mathrm{~T}_{\mathrm{D}}$ \\
& $=7.56+2 \mathrm{~T}_{\mathrm{D}}$ \\
\hline & $\mathrm{T}=\mathrm{T}_{\mathrm{H}}+\mathrm{T}_{\mathrm{M}}+\mathrm{T}_{\mathrm{P}}+\mathrm{T}_{\mathrm{K}}+\mathrm{T}_{\mathrm{M}}+\mathrm{T}_{\mathrm{K}}+\mathrm{T}_{\mathrm{M}}+\mathrm{T}_{\mathrm{K}}$ \\
& $=\mathrm{T}_{\mathrm{H}}+3 \mathrm{~T}_{\mathrm{M}}+\mathrm{T}_{\mathrm{P}}+3 \mathrm{~T}_{\mathrm{K}}$ \\
& $=0.40+4.05+1.1+0.66$ \\
Multi-dimensional & $=6.21$
\end{tabular}




\section{CONCLUSION}

Mobile IPTV has advantages in that diverse terminals that used to be provided on the web and with broadcasting can be serviced for users in the form of content through mobile terminals when they demand it. However, the existing IPTV UIs in service are provider-oriented without consistency in content types, and the menu classification systems are also complex, which limits their applicability to mobile IPTV. Besides, interactions between users and UIs are too difficult to find a content that user wants to watch, so users are highly likely to refine the content from scratch since they couldn't find the right content that they really want.

To improve such drawbacks, the multi-dimensional content browsing menus proposed in the present study classify content largely with diverse browsing criteria for lots of content by use 4 color buttons. As a result, proposed method applied to mobile IPTV UI to enable interactivity between users and the UI and to allow users to find contents on demand easily and intuitively. The proposed UI was compared with the IMDb Android Application, a DB service used around the world to search films, in order to prove its efficiency. As a result of comparing the two using the GOM-KLM model, the performance process was reduced by 3 stages and the performance time by more than $17.9 \%$. However, the limitation of this study is that an experiment was conducted only for one case. Therefore, future studies shall expand on this study and will examine a variety of different cases to evaluate usability and make the application of any mobile device that provides IPTV to the controller possible by syncing the contents search standard to the device.

\section{REFERENCE}

[1] K. Chorianmopoulos, "Personalized and Mobile Digital TV Applications", Multimed Tools Appl, Vol.36, Issue.1-2, 2008, pp.1-10.

[2] S. Jumisko-Pyykkö, M. Weitzel, D. Strohmeier, "Designing for user experience: what to expect from mobile $3 D$ tv and video?" Proceeding of the 1st international conference on Designing interactive user experiences for TV and video, Vol.291, 2008, pp.183-192.

[3] R. Schatz, S. Egger, "Social Interaction Features for Mobile TV Services," IEEE International Symposium on Broadband Multimedia Systems and Broadcasting, 2008, pp.1-6.

[4] K. Sung-Won, Design and simulation of session synchronization system for Linked Play of Videoon-Demand service in heterogeneous devices [a master's dissertation]. Seoul: Sogang University Graduate School of Media Department of Media Technology; 2009.

[5] L. Sun-Young, "Analysis of Mobility and Security Requirements for Mobile IPTV," The Journal of the Korea Contents Association, Vol.5, No. 5, 2009, pp.34-44.

[6] K. Young-Il, C. Chul-hoi, R. Won, L. Ho-Jin, Mobile IPTV Technical Trends and Development Strategy, April, 2010. ETRI Electronics and Telecommunications Trends, Vol.25, No.2.

[7] Ha-Yong Jung, Moonsik Kim, "Performance Analysis of VOD Recommender System using User Viewing Log of KT IPTV," Proceedings of The KISS, Vol.36, No.1(A), 2009. pp.116-121

[8] Keyword: iphone [online database], http://www.apple.com/iphone/

[9] Keyword: Samsung mobile [online database], http://eg.samsungmobile.com/eng/index.jsp

[10] Keyword: nokia [online database], http://www.nokia.com/

[11] C. Peng, Digital Television Applications [a doctoral dissertation]. Helsinki: Helsinki University of Technology; 2002.

[12] C. Jun-ho, K. Dong-kyu, O. Mun-suk, "Gender Differences on the Color Preference of Mobile Internet Display UI:Wibro Phone Skin", Journal of Korean Society of Design Science, Vol.22, No.4, 2009, pp.245-254. 
[13] C. Yoo-Joo, O. Jung-Min, B. Jae-Hee, M. Nam-Mee, "Design of Multi-dimensional Contents Retrieval Browser for IPTV," Journal of the Korea Contents Association, Vol.10, No.8, Aug, 2010, pp.138-146.

[14] C. Jong-Whi, The Efficiency of Soft-key Mapping in Mobile Phones [a master's dissertation]. Seoul: The Graduate School Yonsei University; 2006.

[15] Keyword: $I M D b$ [online database], http://www.imdb.com/features/android/

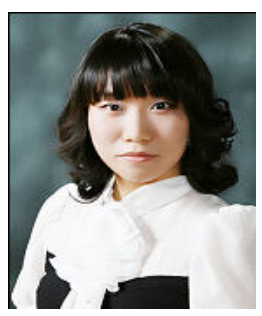

\section{Jaehee Byeon}

She received her B.S. in Computer System from Duksung University. She is currently working towards her M.S. in the Department of IT Application Technology at the Hoseo Graduate School of Venture. Her current research interests include user interface, mobiles, and recommender systems.

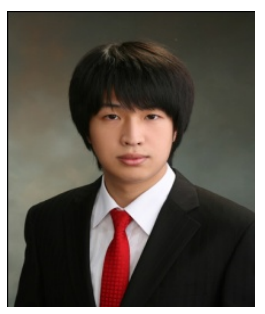

\section{Ju-Hong Song}

He received his B.S. in Computer Engineering from Hoseo University. He is currently working towards his M.S. in the Department of IT Application Technology at the Hoseo Graduate School of Venture. His current research interests include mobile application and recommender systems.

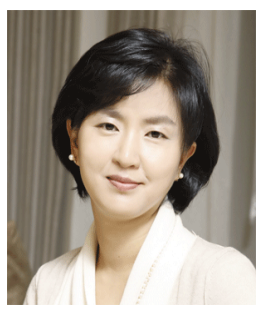

\section{NamMee Moon}

She received her B.S. in Computer Science from Ewha Womans University and her M.S. in Data Base from Ewha Womans University, in 1985 and 1987, respectively. She received her Ph.D. in Computer Technology in 1998 from Ewha Womans University. She joined the Department of IT Application Technology at Hoseo University as an associate professor. Her current research interests include the interactive digital business model, $\mathrm{HCl}$, service oriented interactive video applications, and meta. 